\title{
A brief guideline proposal for using dydrogesterone prevention or treatment of pregnancy disorders
}

\section{Adolf E Schindler* \\ Institute for Medical Research and Education, Essen, Germany}

\section{Introduction}

Only certain progestogens are to be used for pregnant women.

Dydrogesterone is one of the progestogens, which are suitable to be applicated in pregnancy [1].

The following progestogens had been studied:

1. Dydrogesterone (oral)

2. Micronized progesterone (vaginal)

3. 17- Hydroxyprogesterone caproate (intramuscular)

Only dydrogesterone will be considered in this mini review.

All studies with dydrogesterone have been successful looking at threatened miscarriage, recurrent (habitual) miscarriage, preterm labour and preeclampsia provided organic lesions such as myoma or uterine septum have been removed.

In addition, one has to differenciate whether the progestogen is used for prevention or therapy.

The dose used for prevention or treatment has been gradually increased for dydrogesterone and micronized progesterone and the length of time to be used has been extended [2,3].

\section{Threatened miscarriage}

At present, the situation is the following:

Threatened miscarriage is defined as vaginal bleeding, closed cervix and intact fetus by ultrasound.

The pregnant woman receives treatment with dydrogesterone p.o. giving $40 \mathrm{mg}$ at once and thereafter up to $40 \mathrm{mg} / \mathrm{d}(2 \times 20 \mathrm{mg})$ orally. This should be continued until the $37^{\text {th }}$ week of gestation.

Why? It was shown by several publications that women with threatened miscarriage later in pregnancy have higher incidence of preterm labour or preeclampsia, bleeding problems and small for date babies [4-6].

In one of our studies on prevention of preeclampsia using dydrogesterone only up to 16 weeks of gestation, the rate of preterm labor was similar as in the control group, while the incidence of preeclampsia was significantly reduced $(\mathrm{p}<0.001)$ [7].

\section{Conclusion}

In threatened miscarriage therapy should be done by dydrogesterone $40 \mathrm{mg}$ p.o. at once and thereafter $2 \times 20 \mathrm{mg} / \mathrm{d}$ until 37 weeks of gestation.

\section{Recurrent (habitual) miscarriage}

Less frequent but by no means less important is the use of dydrogesterone in women with recurrent (habitual) miscarriage.

Recent large randomized studies using on the one hand dydrogesterone $20 \mathrm{mg} / \mathrm{d}$ up to 20 weeks of gestation [8] and on the other hand a raised dose of micronized progesterone intravaginally of $2 \times 400$ $\mathrm{mg} /$ day up to 12 weeks of gestation [9]. The data for dydrogesterone were leading to a significant reduction of miscarriage, while in the progesterone study there was no significant difference compared with the control group. The rate of life birth was in the progestogen group $65.8 \%$ and for the placebo group $63,3 \%$ (not significant) [9].

\section{Conclusion}

Dydrogesterone $2 \times 20 \mathrm{mg} / \mathrm{d}$ should be used in pregnant women with a history of recurrent (habitual) miscarriage and extended up to 37 weeks of gestation.

\section{Preterm labour}

In 1990 a metaanalysis of the use of 17- $\alpha$ hydroxyprogesterone caproate concluded that a significant reduction of preterm birth and a significant improvement of fetal outcome can be accomplished [10].

But no real practical consequences were drawn. Thereafter, studies with micronized progesterone vaginally (100 to $200 \mathrm{mg} / \mathrm{d}$ ) were used to demonstrate a favourable effect regarding the prevention of preterm labour $[11,12]$.

In addition, to prevent preterm labour in pregnant women with a history of spontaneous preterm labour and preterm delivery could be shown in women with a short cervix [13].

Recently, the effectiveness of micronized progesterone vaginally could not be verified [14].

Publications on dydrogesterone and prevention of preterm labour are limited $[15,16]$

My own unpublished data with dydrogesterone 2 x $20 \mathrm{mg} / \mathrm{d}$ orally and continuously until 37 weeks of gestation where successful. However, further studies are needed.

Correspondence to: Adolf E. Schindler, Institute for Medical Research and Education, University Clinic, Hufelandstrasse 55, D-45122 Essen, Germany, Tel: +49-201-7991833; E-mail: adolf.schindler@uni-due.de

Received: October 17, 2017; Accepted: November 03, 2017; Published: November 06, 2017 


\section{Treatment of preterm labour with progestogens}

When contractions are present, but amniotic membranes are intact, the use of dydrogesterone can stop labour together with a tocolytic or without.

\section{$[15,16]$}

Own unpublished data and results of others have verified this

\section{Conclusion}

1. The use of dydrogesterone $(2 \times 20 \mathrm{mg} / \mathrm{d}$ p.o.) appears to achieve preterm labour/ preterm birth prevention when used from the $16^{\text {th }}$ week of gestation until 37 weeks of gestation. This was shown for a history of previous preterm birth and or a short cervix.

2. Treatment of preterm labour without rupture of the amniotic membranes can be accomplished with $2 \times 20 \mathrm{mg}$ dydrogesterone daily with or without tocolytic drugs.

\section{Prevention of preeclampsia}

Progesterone has been shown to lower systolic and diastolic blood pressure in women and men [17].

Already in 1957 it was reported that with progesterone i.m. the full clinical picture using intramuscular progesterone could be favourable improved [18,19].

The infants of the progesterone treated women appeared to have improved brain function [19].

However, this was discussed, but no further studies have been published.

Later in 1971 and 1982 successful treatment of preeclampsia with progesterone was done, but no further studies have been published $[17,20]$.

In 2014 a prospective, randomized, placebo-controlled trial was published, revealing that dydrogesterone $30 \mathrm{mg} / \mathrm{d}$ p.o. starting within the first 5 days after ovum pick-up until 16 weeks of gestation did lead to a highly significant reduced development of preeclampsia $(\mathrm{p}<0,001)$, incidence $1,7 \%$, in the prevention group and $12,9 \%$ in the control group [20].

Dydrogesterone was started in the first five days after ovum pickup through 16 weeks of gestation.

Looking at other disturbances, like preterm labour, no difference was found [20], when compared with the control group [20]. This fits very well with the clinical findings of achieving preterm labour prevention by treating with a progestogen from the $16^{\text {th }}$ to the $37^{\text {th }}$ week of gestation.

In the meantime, a retrospective study was done with women having ART-treatment and taking dydrogesterone or dydrogesterone/ 17- $\alpha$ hydroxyprogesterone caproate in the same country [21]. Again, a significant reduction of preeclampsia was encountered using the hormone treatment up to $14-16$ weeks of gestation $(\mathrm{p}<0.05)$ [21]. There was no difference between the dydrogesterone group and dydrogesterone/17- $\alpha$ hydroxyprogesterone caproate group $(6,9 \%$ versus $9,9 \% ; \mathrm{p}=0.2)[21]$.

A favourable effect of dydrogesterone has also been reported for 30 mg dydrogesterone from early pregnancy until $37^{\text {th }}$ week of gestation in a high-risk woman for preeclampsia prevention [22].

\section{Conclusion}

At present, it appears that early use of dydrogesterone $(2 \times 20 \mathrm{mg} / \mathrm{d}$ up to $16^{\text {th }}$ week of gestation) prevents the development of preeclampsia highly significant. A continuation up to $37^{\text {th }}$ week of gestation might further improve the effect and is also effective for prevention of preterm labour.

\section{References}

1. Schindler AE, Campagnoli C, Druckmann R, Huber J, Pasqualini JR, et al. (2003) Classification and pharmacology of progestins. Maturitas 46 Suppl 1: S7-7S16. [Crossref]

2. Schindler AE (2015) Progestogens and Pregnancy J. Reproduktionsmed. Endokrinol. 12:377-379

3. Schindler AE, Campagnoli C, Druckmann R, Huber J, Pasqualini JR, et al. (2003) Classification and pharmacology of progestins. Maturitas 46 Suppl 1: S7-7S16. [Crossref]

4. Saraswat L, Bhattacharya S, Maheshwan A, Bhattacharya S. (2010) Maternal and perinatal outcome in women with threatened miscarriage in the first trimester: A systematic review BJOG 117: 245-257 [Crossref]

5. Jauniaux E, Vav Oppenraaji RHF, Burton GJ (2010) Obstetric outcome after early placental complications Curr. Opin. Obstet. Gynecol. 22: 452-457

6. Ahmed SR, El-Sammani Mel-K, Al-Sheeha MA, Aitallah AS, Jabin Khan F, et al (2012) Pregnancy outcome in women with threatened miscarriage: a year study. Mater Sociomed 24: 26-28. [Crossref]

7. Zaimul RMR, Lim JF, Nawavi NH, Lugman M, Zolkeplai MF, et al. (2014) A pilo study to determine wether progestogen supplementation using dydrogesterone during the first trimester will reduce the incidence of gestational hypertension in pregnancy Gynecol. Endocrinol.30: 217-220 [Crossref]

8. Kumar A, Begum N, Prasad S, Aggarwal S (2014) Oral dydrogesterone treatmen during early pregnancy to prevent recurrent pregnancy loss and its role in modulation of cytokine production: a double-blind, randomized, parallel, placebo-controlled trial. Fert. Steril. 102:1357-1363. [Crossref]

9. Coomarasamy A, Williams H, Truchanowicz E, Seed PT, Small R, et al. (2015) A Randomized Trial of Progesterone in Women with Recurrent Miscarriages. $N$ Engl $J$ Med 373: 2141-2148. [Crossref]

10. Keirse MJ (1990) Progestogen administration in pregnancy may prevent preterm delivery. Br J Obstet Gynaecol 97: 149-154. [Crossref]

11. Schindler AE (2004) [Prevention of preterm delivery with gestagens]. Z Geburtshilfe Neonatol 208: 165-169. [Crossref]

12. Schindler AE (2010) Progestogens for treatment and prevention of pregnancy disorders. Horm Mol Biol Clin Investig 3: 453-460. [Crossref]

13. Conde-Agualewa A, Romero R. Vaginal progesterone to prevent preterm bith in pregnant women with a sonographic short cervix: Clinical and public health implications. Am. J. Obstet. Gynecol. 2016; 214: 235-242

14. Norman JE, Marlow N, Messow CM, Shennan A, Bennett PR et al. (2016) Vaginal progesterone prophylaxis for preterm birth (the OPPTIMM Study): A multicenter, randomized, double-blind trial. Lancet 387: 2106-2116 [Crossref]

15. Hudic H, Skekeres-Bartho J, Fatusic Z et al. (2011) Dydrogesterone supplementation in women with threatened preterm delivery - the impact on cytokine profile, hormone profile and progesterone induced blocking factor. J. Reprod. Immunol. 92: 103-107 [Crossref]

16. Hudic I, Schindler AE, Szekeres-Bartho J, Stray-Pedersen B (2016) Dydrogesterone and pre-term birth. Horm Mol Biol Clin Investig 27: 81-83. [Crossref]

17. Ragab MI, Sammour MB, ElKabarity H, Hegazy MR (1971) Progesterone: a treatmen for preeclamptic toxaemia. Ain Shams Med. J. 22: 9-24

18. DALTON K (1957) Toxaemia of pregnancy treated with progesterone during the symptomatic stage. $\mathrm{Br}$ Med $\mathrm{J}$ 2: 378-381. [Crossref]

19. Dalton K (1962) Controlled trials in the prophylactic value of progesterone in the treatment of preeclamptic toxaemia. Brit. Commonw. Obstet. Gynecol. 69: 463-468

20. Zaimul RMR, Lim JF, Nawavi NH, Lugman M, Zolkeplai MF, et al. (2014) A pilot study to determine wether progestogen supplementation using dydrogesterone during the first trimester will reduce the incidence of gestational hypertension in pregnancy Gynecol. Endocrinol. 30: 217-220 [Crossref] 
Schindler AE (2017) A brief guideline proposal for using dydrogesterone prevention or treatment of pregnancy disorders

21. Ali AB, Ahmad MFB, Kwang WB, Shan LP, Shafis NM, et al. (2016) Dydrogesterone support following assisted reproductive technique (ART) reduces the risk of preeclampsia. Horm Mol Biol Clin Investig. 27:93-96 [Crossref]
22. Tskhay VB, Kovtun NM, Schindler AE (2016) Successful prevention of preeclampsia in a high-risk pregnancy using progestogen dydrogesterone: a clinical case. Horm $\mathrm{Mol}$ Biol Clin Investig 27: 85-88. [Crossref]

Copyright: (C2017 Schindler AE. This is an open-access article distributed under the terms of the Creative Commons Attribution License, which permits unrestricted use, distribution, and reproduction in any medium, provided the original author and source are credited. 